\title{
Nicotinamide phosphoribosyltransferase inhibition reduces intraplaque CXCL1 production and associated neutrophil infiltration in athero- sclerotic mice
}

\author{
Alessio Nencioni'; Rafaela F. da Silva ${ }^{2,3}$; Rodrigo A. Fraga-Silva2,3; Sabine Steffens ${ }^{4}$; Mathias Fabre5; Inga Bauer'; Irene Caffa'; \\ Mirko Magnone ${ }^{6}$; Giovanna Sociali6; Alessandra Quercioli5; Graziano Pelli5; Sébastien Lenglet ${ }^{5}$; Katia Galan ${ }^{5}$; Fabienne Burger ${ }^{5}$; \\ Sara Vázquez Calvo5; Maria Bertolotto7; Santina Bruzzone ${ }^{6}$; Alberto Ballestrero'; Franco Patrone'; Franco Dallegri7; \\ Robson A. S. Santos ${ }^{3}$; Nikolaos Stergiopulos; François Mach5; Nicolas Vuilleumier8; Fabrizio Montecucco ${ }^{5,7}$ \\ ${ }^{1}$ Department of Internal Medicine, University of Genoa, Genoa, Italy; ${ }^{2}$ Institute of Bioengineering, Ecole Polytechnique Fédérale de Lausanne, Lausanne, Switzerland; ${ }^{3}$ Department \\ of Physiology and Biophysics, Federal University of Minas Gerais, Belo Horizonte, Minas Gerais, Brazil; ${ }^{4}$ Clinical Pathobiochemistry, Institute for Cardiovascular Prevention, Ludwig- \\ Maximilians-University Munich and German Centre for Cardiovascular Research (DZHK), partner site Munich Heart Alliance, Munich, Germany; ${ }^{5}$ Division of Cardiology, Foundation \\ for Medical Researches, University of Geneva, Geneva, Switzerland; ${ }^{6}$ Department of Experimental Medicine, Section of Biochemistry, and CEBR, University of Genoa, Genoa, Italy; \\ ${ }^{7}$ First Clinic of Internal Medicine, Department of Internal Medicine, University of Genoa School of Medicine, IRCCS Azienda Ospedaliera Universitaria San Martino-IST Istituto \\ Nazionale per la Ricerca sul Cancro, Genoa, Italy; ${ }^{8}$ Division of Laboratory Medicine, Department of Genetics and Laboratory Medicine, Geneva University Hospitals, Geneva, \\ Switzerland
}

\begin{abstract}
Summary
Pharmacological treatments targeting CXC chemokines and the associated neutrophil activation and recruitment into atherosclerotic plaques hold promise for treating cardiovascular disorders. Therefore, we investigated whether FK866, a nicotinamide phosphoribosyltransferase (NAMPT) inhibitor with anti-inflammatory properties that we recently found to reduce neutrophil recruitment into the ischaemic myocardium, would exert beneficial effects in a mouse atherosclerosis model. Atherosclerotic plaque formation was induced by carotid cast implantation in ApoE-I- mice that were fed with a Western-type diet. FK866 or vehicle were administrated intraperitoneally from week 8 until week 11 of the diet. Treatment with FK866 reduced neutrophil infiltration and MMP-9 content and increased collagen levels in atherosclerotic plaques compared to vehicle. No effect on other histological parameters, including intraplaque lipids or macrophages, was ob-
\end{abstract}

Correspondence to:

Dr. Fabrizio Montecucco, MD, PhD

Cardiology Division, Foundation for Medical Researches

Department of Internal Medicine, University of Geneva

64 Avenue Roseraie, 1211 Geneva, Switzerland

Tel.: +41 2238272 38, Fax: +41 223827245

E-mail: Fabrizio.montecucco@unige.ch

and

Dr. Alessio Nencioni, MD

Department of Internal Medicine, University of Genova

Viale Benedetto XV, 6, 16132 Genova, Italy

Tel.: +39 010353 8990, Fax: +39 0103538945

E-mail: alessio.nencioni@unige.it served. These findings were associated with a reduction in both systemic and intraplaque CXCL1 levels in FK866-treated mice. In vitro, FK866 did not affect MMP-9 release by neutrophils, but it strongly reduced CXCL1 production by endothelial cells which, in the in vivo model, were identified as a main CXCL1 source at the plaque level. CXCL1 synthesis inhibition by FK866 appears to reflect interference with nuclear factor-KB signalling as shown by reduced $\mathrm{p} 65$ nuclear levels in endothelial cells pre-treated with FK866. In conclusion, pharmacological inhibition of NAMPT activity mitigates inflammation in atherosclerotic plaques by reducing CXCL1-mediated activities on neutrophils. These results support further assessments of NAMPT inhibitors for the potential prevention of plaque vulnerability.

\section{Keywords}

Carotid artery, inflammation, atherosclerosis

Received: July 2, 2013

Accepted after major revision: September 30, 2013

Prepublished online: November 7, 2013

doi:10.1160/TH13-07-0531

Thromb Haemost 2014; 111: 308-322

\section{Introduction}

Studies show that nicotinamide adenine dinucleotide $\left(\mathrm{NAD}^{+}\right)$ plays a key role in immune cell function (1-4). In particular, nicotinamide phosphoribosyltransferase (NAMPT), the key enzyme for $\mathrm{NAD}^{+}$biosynthesis from nicotinamide, has emerged as the hub of several signalling cascades that all converge to promote inflammation (1-4). Consistent with this role of NAMPT in immunity, FK866, a potent and specific NAMPT inhibitor which lowers
$\mathrm{NAD}^{+}$levels (5), exerts anti-inflammatory effects in several animal disease models, including arthritis, experimental polymicrobial sepsis, autoimmune encephalomyelitis, D-galactosamine/LPSinduced hepatitis and myocardial ischaemia/reperfusion $(1-4,6)$.

A chronic inflammatory response of the arterial wall is one of the key pathophysiological events in atherosclerosis (7). In particular, recent studies demonstrate the importance of neutrophil recruitment and degranulation orchestrated by CC and CXC chemokines in atherogenesis, both in humans and in animal models 
(8). Notably, neutrophil infiltration was shown to be especially high in symptomatic carotid lesions, indicating that this leukocyte subset may indeed be a viable target for treating atherosclerosis and for preventing its acute complications (9-11). Pharmacologic interventions directed to block the synthesis or the bioactivities of neutrophil chemokines were shown to abrogate atherogenesis in preclinical models $(8,12-14)$. For instance, Evasin-3, a CXC chemokine binding protein that inhibits CXCL1-mediated bioactivity, reduces neutrophilic infiltration and associated carotid plaque vulnerability in mice (12). However, despite these encouraging premises, major concerns have been raised that specific anti-chemokine treatments may have limited efficacy or entail allergic or immunosuppressive adverse events in humans $(8,13,14)$.

Atheromas express high levels of NAMPT and the expression of this enzyme was found to be even higher in plaques from symptomatic patients, suggesting a pathophysiological role for NAMPTdependent $\mathrm{NAD}^{+}$-biosynthesis in atherogenesis and plaque destabilisation (15). Potential mechanisms through which NAMPT may promote plaque vulnerability include its ability to stimulate the secretion of pro-inflammatory cytokines and chemokines (such as tumour necrosis factor-alpha [TNF- $\alpha$, interleukin [IL]1, IL6, CCL2), to increase matrix metalloproteinase (MMP) release, and to prevent apoptosis in vascular and immune cells (4). However, despite these premises, the effects of pharmacological NAMPT inhibition on vulnerability parameters of atherosclerotic plaques and on intraplaque inflammatory patterns have never been formally investigated.

Here, we set out to determine the therapeutic potential of FK866 in a mouse model of shear stress-induced carotid atherosclerosis that was developed by Krams et al. (16). This model was selected for this study since it allows to assess the potential benefits of an experimental treatment on atherosclerotic plaques that develop in different anatomic positions (namely in carotids vs aortic roots) and have different phenotypes and degrees of vulnerability $(10,16)$. In addition, we aimed to determine, both in vivo and in vitro, the cellular and molecular mechanisms that underlie the beneficial activity of NAMPT inhibition.

\section{Materials and methods}

\section{Mouse model of shear stress-induced atherogenesis and plaque vulnerability}

Apolipoprotein E-deficient $\left(\mathrm{ApoE}^{-/-}\right.$) adult mice (15-20 week of age) in a C57BL/6J background were obtained from The Charles River Laboratories (Wilmington, MA, USA) and randomly assigned to receive either Vehicle (0.1\% DMSO in phosphate-buffered saline $[P B S], n=12$ ) or the selective NAMPT inhibitor (FK866, n=11) treatment. During the experimental period, all animals were fed with a Western-type diet consisting of 15\% (wt/wt) cocoa butter and 0.25\% (wt/wt) cholesterol (Diet W; abDiets). After a two-week period of Western diet, shear stress in the right common carotid artery was altered by the surgical placement of a "cast" device, as previously described (16). Nine weeks after surgery, the animals were euthanised to collect tissue and serum samples. During the last three weeks before euthanising (from week 6 to 9 of cast implantation), mice were intraperitoneally injected with FK866 (10 mg/kg, b.i.d. for five consecutive days every week, provided by NIMH Chemical Synthesis and Drug Supply Program) or equivalent volume of control Vehicle (0.1\% DMSO in PBS, $200 \mu \mathrm{l} /$ mouse). The dose and the treatment schedule were planned on the basis of recently published experiments in mice and in vitro $(1,2)$, showing marked efficacy to reduce in vivo neutrophil infiltration within inflamed tissues and in vivo results on systemic $\mathrm{NAD}^{+}$depletion in FK866-treated mice (2). In the experiments aimed to define the effects of FK866 on blood cell counts, 8-week aged $\mathrm{ApoE}^{-/-}$mice ( $\mathrm{n}=4-5$ per group) were fed a high cholesterol diet (HCD; 1.25\% cholesterol, 0\% cholate; Research Diets; D12108) for two weeks. No surgical procedure was performed in these mice until sacrifice. During the last week before euthanasia, mice were injected intraperitoneally with FK866 (10 mg/kg, b.i.d. for five consecutive days) or the equivalent volume of control Vehicle (0.1\% DMSO in PBS, $200 \mathrm{microl} / \mathrm{mouse})$. Afterward, at sacrifice, blood neutrophil and monocyte counts were determined (see below).

Mice well tolerated the treatment and no animal death was reported during the study protocols. These mouse protocols were approved by local ethics committee ("Commision pour l'expérimentation Animale" of Canton Vaud) and Swiss authorities and conformed to the "position of the American Heart Association on Research Animal Use" and to ARRIVE guidelines.

\section{Detection of inflammatory mediators in mouse serum}

Mouse serum levels of CCL2, CXCL1 and CXCL2 were measured by colorimetric enzyme-linked immunosorbent assay (ELISA, R\&D Systems, Minneapolis, MN, USA), following manufacturer's instructions. The limits of detection for ELISA were $3.9 \mathrm{pg} / \mathrm{ml}$ for CCL2, $15.625 \mathrm{pg} / \mathrm{ml}$ for CXCL1, and $15.625 \mathrm{pg} / \mathrm{ml}$ for CXCL2. Mean intra- and inter-assay coefficients of variation (CV) were below $8 \%$ for both markers. Serum triglycerides, total cholesterol, low-density lipoprotein cholesterol (LDL-c), high-density lipoprotein cholesterol (HDL-c), free fatty acids were routinely measured and expressed in mmol/l. Circulating neutrophil and monocyte counts were assessed by both flow cytometry (FACS) (17) and classical morphometric analysis (Hematocytometer; Sysmex Digitana AG, Horgen, Switzerland), as previously described. After red blood cell lysis, staining for flow cytometry was performed with following antibodies: CD45-FITC (104, BD Biosciences, San Diego, CA, USA), Ly6G-PE (1A8, BD Biosciences), CD11b-PerCP (M1/70, BioLegend) and CD115-APC (AFS98, from eBioscience, San Diego, CA, USA). All flow cytometry samples were collected with the FACSCanto II flow cytometer and analysed with FACSDiva Software (BD Biosciences).

\section{Immunohistochemistry in atherosclerotic plaques}

Mouse carotid artery was macroscopically cut in three portions: upstream region of the cast device (low shear stress [LSS]), at cast level (high shear stress [HSS]) and downstream of the cast (oscilla- 
tory shear stress [OSS]) and frozen in OCT. LSS and OSS portions and aortic sinus from all mice were serially cut in $7 \mu \mathrm{m}$ transversal sections, as described previously (10). The sections (eleven sections per stainings with $90 \mu \mathrm{m}$ intervals) from mouse specimens were fixed in acetone and immunostained with specific antibodies CD68 (macrophages, ABD Serotec, Düsseldorf, Germany), antimouse Ly-6G (neutrophils, BD Pharmingen ${ }^{\text {тм }}$, San Jose, CA, USA), anti-mouse CXCL1 (Santa Cruz Biotechnology), anti-mouse MMP-9 (R\&D Systems) and anti-mouse CD62E (activated endothelial cells, Bioss Inc. Woburn, MA, USA) (18). Quantifications were performed using the MetaMorph software. Results for other parameters were calculated as percentages of stained area on total lesion area or number of infiltrating cells per $\mathrm{mm}^{2}$ of lesion area.

\section{Oil Red 0 staining for lipid content}

Eleven sections per mouse carotid LSS and OSS and five sections per mouse aortic sinus were stained with Oil Red O, as previously described (10). Sections and aortas were counterstained with Mayer's hemalun and rinsed in distilled water. Quantifications were performed using the MetaMorph software. Data were calculated as ratios of stained area on total lesion area.

\section{Sirius red staining for collagen content}

Eleven sections per mouse carotid LSS and OSS and five sections per mouse aortic sinus were rinsed with water and incubated with $0.1 \%$ Sirius red (Sigma Chemical Co, St Louis, MO, USA) in saturated picric acid for 90 minutes (min). Sections were rinsed twice with $0.01 \mathrm{~N} \mathrm{HCl}$ for $1 \mathrm{~min}$ and then immersed in water. After dehydration with ethanol for 30 seconds (sec) and cover-slipping, the sections were photographed with identical exposure settings under ordinary polychromatic or polarised light microscopy. Total collagen content was evaluated under polychromatic light. Interstitial collagen subtypes were evaluated using polarised light illumination; under this condition thicker type I collagen fibers appeared orange or red, whereas thinner type III collagen fibers were yellow or green (10). Quantifications were performed with MetaMorph software. Data were calculated as percentages of stained area on total lesion area.

\section{Apoptotic cell measurement within atherosclerotic plaques}

We performed staining of frozen sections with the Dead End ${ }^{\mathrm{m}}$ colourimetric terminal deoxinucleotidyltransferase-mediated dUTP nick end labelling (TUNEL) system (Promega, Madison, WI, USA) using diaminobenzidine as the chromogenic substrate (according to the manufacturer's instructions). Results were expressed as percentages of stained area on total plaque area.

\section{Human primary neutrophil isolation and culture}

Neutrophils were obtained from healthy volunteers after signature of an informed consent. The local ethical committee approved the investigation protocol, and it was conformed to the principles outlined in the Declaration of Helsinki. Human neutrophils were isolated as previously described (2). The neutrophil isolation protocol was completed in 2 hours (h) from the blood sampling. Neutrophil purity was determined by morphologic analysis of Giemsa-stained cytopreparations (from Merck, Darmstadt, Germany) and confirmed $>97 \%$. Then, cells were resuspended in culture medium (serum-free RPMI 1640 medium containing 25 mmol/l Hepes). Neutrophils $\left(5 \times 10^{5}\right.$ cells per well) were incubated for $6 \mathrm{~h}$ at $37^{\circ} \mathrm{C}$ in the presence or the absence of different concentrations (up to 100 $\mathrm{nM}$ ) of FK688 in polystyrene plates. Then, cells were stimulated in the presence or absence of $10 \mathrm{ng} / \mathrm{ml}$ phorbol-12-myristate13-acetate (PMA, positive control from Sigma-Aldrich, Buchs, Switzerland) (20), or $100 \mathrm{ng} / \mathrm{ml}$ of human recombinant TNF- $\alpha$ (R\&D Systems) for $30 \mathrm{~min}$ at $37^{\circ} \mathrm{C}$ in a humidified atmosphere $5 \%$ $\mathrm{CO}_{2}$. TNF was used to better mimic intraplaque atherosclerotic inflammation, which is characterised by increased TNF levels (19). Levels of matrix metalloproteinase (MMP)-9, MMP-8, myeloperoxidase (MPO), (all from R\&D Systems) released in the cell supernatants were measured by ELISA, by following manufacturer's instructions. The limits of detection were $0.312 \mathrm{ng} / \mathrm{ml}$ for MMP-9, $0.156 \mathrm{ng} / \mathrm{ml}$ for MMP-8, $1.56 \mathrm{ng} / \mathrm{ml}$ for MPO. Mean intra- and inter-assay coefficients of variation $(\mathrm{CV})$ were below $6 \%$.

\section{Pro-MMP-9 zymographic assay}

Pro-MMP-9 zymographic activity in cell supernatants was assessed. 9\% SDS-polyacrylamide gels were copolymerised with gelatin (Sigma). Equal volume of cell supernatants $(35 \mu \mathrm{l})$ and $1 \mathrm{ng}$ of recombinant human pro-MMP-9 standard (Calbiochem, Lucern, Switzerland) were loaded on gels in the absence of reducing agents. Then, gels were rinsed and stained with Coomassie Blue $\mathrm{R}-250$. Zymographic results were expressed as pro-MMP-9 proteolytic activity and calculated on the basis of the following formula: Serum/supernatant pro-MMP-9 $=\left(\mathrm{I}_{\text {obs }} / \mathrm{I}_{\text {std }}\right) \times \mathrm{W}_{\text {std }}$, where $\mathrm{I}_{\text {obs }}$ and $\mathrm{I}_{\mathrm{std}}$ are intensities of lytic areas produced in gels by samples and by standard pro-MMP-9, and $\mathrm{W}_{\text {std }}$ is the weight ( $1 \mathrm{ng}$ ) of standard pro-MMP-9 loaded onto the gel. Zymographic data were expressed as $\mu \mathrm{g} / \mathrm{ml}$. Gelatinolytic bands were measured with a gel analysis system (GeneGenius, Syngene, Cambridge, UK).

\section{Human endothelial cell culture, chemokine secretion and cell viability}

Human vascular endothelial cells (HECV) were a kind gift from Dr. Alessandra Puddu (Department of Internal Medicine, University of Genoa, Genoa, Italy). These cells were maintained in DMEM high glucose medium supplemented with $10 \%$ fetal bovine serum (FBS), $2 \mathrm{mM}$ L-glutamine, $50 \mathrm{U} / \mathrm{ml}$ penicillin and $50 \mu \mathrm{g} / \mathrm{ml}$ streptomycin (Life Technologies Carlsbad, CA, USA). BAY-11-7082 was purchased from Sigma Aldrich. HECV cells (2.5 x 104 cells/well) were seeded in 12-well plates in $1 \mathrm{ml}$ growth medium. The day after, $10 \mathrm{nM}$ FK866 was added (or not) to the medium [pre-incubation with FK866 (24 h)]. Twenty-four hours later, $10 \mu \mathrm{M}$ BAY-11-7082 was added (or not) to the cell medium 
[pre-incubation with BAY 11-7082 (30 min)]. Finally, 30 min later, cells were stimulated (or not) with $10 \mathrm{ng} / \mathrm{ml}$ TNF- $\alpha$. Supernatants were collected $24 \mathrm{~h}$ later and assayed for CXCL1, CXCL2 and CCL2 using a commercially available DuoSet ${ }^{\oplus}$ ELISA kit (R\&D Systems). Chemokine concentrations in cell supernatants were normalised to cell density as measured with sulforhodamine B (20). For viability assays, HECV cells $\left(1.6 \times 10^{4}\right.$ cells/well) were plated in 24-well plates and allowed to adhere. Vehicle (1\%o DMSO) or 10 nM FK866 were added and viability was determined at $48 \mathrm{~h}$ of incubation in standard Annexin-V/propidium iodide (PI, Sigma Aldrich) assays. Floating and adhering cells were collected from culture wells by repeatedly washing and by subsequent trypsinisation. Subsequently, cells were stained with AnnexinV-FITC (Becton Dickinson Italia, Milan, Italy) and PI $(1 \mu \mathrm{g} / \mathrm{ml})$, according to the manufacturer's instructions and analysed by flow cytometry with a FACS Calibur (Becton Dickinson). A total of 20,000 events for each sample were acquired. Cells were also imaged at room temperature using with the 10X magnification of a Leica DMI 3000B microscope, a Leica DFC425C camera, and the software Leica Application Suite 3.6.0. Annexin-V single-positive cells were considered as early apoptotic cells, whereas AnnexinV/PI double-positive cells were considered as late apoptotic/necrotic cells. Results were expressed as percentages of positive cells of the total cells counted.

\section{Determination of intracellular NAD+ levels}

For intracellular $\mathrm{NAD}^{+}$content determination, $1.5 \times 10^{5}$ cells/well were plated in six-well plates, allowed to adhere and subsequently treated for $24 \mathrm{~h}$ in the presence or absence of $10 \mathrm{nM}$ FK866. Thereafter, adhering cells were lysed with $0.6 \mathrm{M}$ perchloric acid (PCA). Cell extracts were neutralised and $\mathrm{NAD}^{+}$concentration was assessed with a sensitive enzyme cyclic assay, which exploits the use of alcohol dehydrogenase or of G6PD, to determine $\mathrm{NAD}^{+}(21)$.

\section{Nuclear extracts preparation and western blotting detection of nuclear factor (NF)-KB}

HECV cells $\left(1 \times 10^{5}\right)$ were plated in $10 \mathrm{~cm}$ plates and allowed to adhere overnight. Subsequently, cells were treated with or without 10 nM FK866 for $48 \mathrm{~h}$. Thereafter, cells were stimulated with $10 \mathrm{ng} /$ $\mathrm{ml} \mathrm{TNF-} \alpha$ for 5, 15 and $30 \mathrm{~min}$ before being used for nuclear extract preparation. For nuclear extract preparation, cells were washed in $5 \mathrm{ml}$ of ice-cold PBS, mechanically detached from the plates with a cell scraper and washed twice with PBS containing $0.2 \mathrm{mM} \mathrm{Na}_{3} \mathrm{VO}_{4}$. Thereafter, cells were centrifuged at 12,000 rpm for $15 \mathrm{sec}$, the supernatants were removed and the pellets were incubated for $15 \mathrm{~min}$ on ice in $400 \mu \mathrm{l}$ cold buffer A [10 mM HEPES (pH 7.9), 10 mM KCl, 0.1 mM EGTA, 0.1 mM EDTA, 1 mM DTT, $0.5 \mathrm{mM}$ PMSF, $1 \mathrm{mM} \mathrm{Na3VO} 4$ and 1:1,000 Protease Inhibitor Cocktail (Sigma Aldrich)]. After addition of $25 \mu \mathrm{l} 10 \%$ NP-40, these preparations were vortexed and centrifuged at $14,000 \mathrm{rpm}$ for $30 \mathrm{sec}$. Pellets were resuspended in $50 \mu \mathrm{l}$ buffer B $(20 \mathrm{mM}$ HEPES (pH 7.9), 0.4 M NaCl, 0.1 mM EDTA, 0.1 EGTA, 1 mM DTT, $1 \mathrm{mM}$ PMSF, $1 \mathrm{mM} \mathrm{Na3VO} 4$ and 1:1000 Protease Inhibitor
Cocktail) and nuclei were mechanically lysed for $45 \mathrm{~min}$ at $4^{\circ} \mathrm{C}$. The cell debris was pelleted for $10 \mathrm{~min}$ at $12,000 \mathrm{rpm}$, and supernatants were recovered and stored at $-20^{\circ} \mathrm{C}$ until use. Then, $1 \mathrm{mM}$ DTT, $1 \mathrm{mM}$ PMSF, $1 \mathrm{mM} \mathrm{Na}_{3} \mathrm{VO}_{4}$ and 1:1,000 Protease inhibitors were added to buffers just before use. Protein concentration of nuclear extracts was determined by standard Bradford assays. Thirty $\mu \mathrm{g}$ of total proteins were separated by PAGE and, blotted onto a polyvinylidene difluoride membrane. Membranes were probed with a polyclonal rabbit p65 NF- $\kappa$ B antibody (Santa Cruz Biotechnology, Santa Cruz, CA, USA) and bands were visualised by standard ECL. Membranes were then stripped, reblocked, and reprobed to detect total $\beta$-actin (Santa Cruz Biotechnology). Values were normalised to total amounts of $\beta$-actin, respectively, and expressed as percentages of medium control (defined as 100\%).

\section{Western blotting with total cell lysates}

HECV cells $\left(8 \times 10^{4}\right)$ were plated in six-well plates and allowed to overnight adhere. Then, cells were incubated with FK866 (10 and $100 \mathrm{nM}$ ) for additional $48 \mathrm{~h}$ and used for cytosolic extract preparation. Cellular pellets were lysed with $5 \mathrm{mM}$ Tris phosphate, $0.2 \%$ Triton $^{\circledast} \mathrm{X}$-100, $0.4 \mathrm{mM}$ DTT, $0.4 \mathrm{mM}$ 1,2-diaminocyclohexane$\mathrm{N}, \mathrm{N}, \mathrm{N}^{\prime}, \mathrm{N}^{\prime}$-tetraacetic acid and $2 \%$ glycerol. Protein concentration was determined according to standard Bradford assay. Proteins (40 $\mu \mathrm{g}$ ) were separated by SDS-PAGE, transferred to a PVDF membrane (Immobilon-P, Millipore S.p.A., Vimodrone, Italy), and detected with the following antibodies: anti-PBEF (A300-372A Bethyl Laboratories), anti- $\beta$-actin (C4, Santa Cruz Biotechnology). Band intensities were quantified by Quantity One SW software (Bio-Rad Laboratories, Inc, Hercules, CA, USA) using standard ECL.

\section{Statistical analysis}

The Mann-Whitney nonparametric test (the normality assumption of the variables' distribution in both groups was violated) was used for comparisons of continuous variables. Kruskal-Wallis oneway analysis of variance was used for multiple group comparison. Results were expressed as medians (interquartile range [IQR]). Values of $\mathrm{p}<0.05$ (two-tailed) were considered significant. All analyses were done with GraphPad Instat software version 3.05 (GraphPad Software).

\section{Results}

\section{Treatment with FK866 improves histological parameters of plaque vulnerability in a mouse model of shear stress-induced carotid atherosclerosis}

To determine the effect of pharmacological NAMPT inhibition on the inflammatory and vulnerability patterns that characterise carotid and aortic root plaques (plaques developed in the same animals, but characterised by different degrees of vulnerability) (16), we administered FK866 according to a previously established schedule to $\mathrm{ApoE}^{-/-}$mice starting from six weeks after cast place- 


\begin{tabular}{|l|l|l|l}
\hline Mouse profile & Vehicle-treated mice $(\mathbf{n}=12)$ & FK866-treated mice $(\mathbf{n}=11)$ & P-value \\
\hline Body weight $(\mathrm{g})$ & $30.6(29.20,33.30)$ & $29.6(28.90,32.30)$ & 0.4984 \\
\hline Total cholesterol $(\mathrm{mmol} / \mathrm{l})$ & $25.08(21.19,27.26)$ & $27.27(23.90,29.64)$ & 0.2875 \\
\hline LDL cholesterol $(\mathrm{mmol} / \mathrm{l})$ & $19.43(17.77,22.37)$ & $21.72(20.62,23.42)$ & 0.1037 \\
\hline HDL cholesterol $(\mathrm{mmol} / \mathrm{l})$ & $3.93(3.37,4.88)$ & $3.91(3.37,4.30)$ & 0.5254 \\
\hline Triglycerides $(\mathrm{mmol} / \mathrm{l})$ & $0.75(0.67,1.16)$ & $1.05(0.96,2.02)$ & 0.0164 \\
\hline Free fatty acids $(\mathrm{mmol} / \mathrm{l})$ & $0.54(0.43,0.67)$ & $0.58(0.28,0.69)$ & 0.7021 \\
\hline CCL2 $(\mathrm{pg} / \mathrm{ml})$ & $22.70(17.18,38.35)$ & $28.97(16.56,38.48)$ & 0.9279 \\
\hline CXCL1 $(\mathrm{pg} / \mathrm{ml})$ & $59.45(31.34,132.94)$ & $18.57(15.63,57.41)$ & 0.0454 \\
\hline CXCL2 $(\mathrm{pg} / \mathrm{ml})$ & N.D. ${ }^{*}$ & N.D. & N.A.\# \\
\hline
\end{tabular}

Table 1: Mouse body weight, serum lipid and chemokine profile at sacrifice.

Data are expressed as medians (interquartile range). P-value calculated according to U Mann-Whitney test. * N.D.: non-detectable. \# N.A.: not applicable.

ment and for a total of three weeks $(1,2)$. Thereafter, animals were sacrificed and used for histological and serological assessments. Histological parameters of plaque vulnerability were assessed for both treatment groups within the aortic roots and in the LSS and OSS regions of carotid arteries. At sacrifice, no significant differences were found between FK866- and vehicle-treated mice in terms of body weight, serum total cholesterol, LDL-cholesterol,
HDL-cholesterol and free-fatty acids ( $>$ Table 1 ). Serum triglyceride levels were increased in FK866-treated mice compared to controls ( Table 1). Treatment with FK866 was associated with a reduction in the serum levels of CXC chemokines (i.e. CXCL1), but not of CC chemokines (i.e. CCL2) ( Table 1). Confirming previous results (12), serum CXCL2 levels were undetectable (below the lower range of detection: $15.625 \mathrm{pg} / \mathrm{ml}$ ) in $\mathrm{ApoE}^{-/-}$mice on the

\begin{tabular}{|l|l|l|l}
\hline Parameters & Vehicle-treated mice $(\mathbf{n}=12)$ & FK866-treated mice $(\mathbf{n}=11)$ & P-value \\
\hline Carotid LSS & & & \\
\hline Oil-red-0, $\times 10^{3} \mathrm{~mm}^{2}$ & $753.24(405.60,1218.38)$ & $1059.70(743.49,1493.89)$ & 0.3470 \\
\hline Macrophage+ area, \% & $49.81(13.68,80.93)$ & $23.26(18.06,50.39)$ & 0.2426 \\
\hline Neutrophils/mm & $10.07(1.74,52.55)$ & $2.35(1.15,4.75)$ & 0.0400 \\
\hline MMP*-9, \% & $13.24(9.01,39.19)$ & $7.37(3.31,13.50)$ & 0.0400 \\
\hline CXCL1, \% & $9.04(5.11,14.60)$ & $3.34(0.23,6.28)$ & 0.0281 \\
\hline Total collagen, \% & $10.39(2.80,15.14)$ & $15.87(10.31,22.28)$ & 0.0759 \\
\hline Carotid 0SS & & & \\
\hline Oil-red-0, $\times 10^{3} \mathrm{~mm}^{2}$ & $590.43(217.92,1179.72)$ & $680.97(171.95,1162.26)$ & 0.8470 \\
\hline Macrophage+ area, \% & $4.37(0.95,6.07)$ & $5.62(1.31,25.19)$ & 0.6063 \\
\hline Neutrophils/mm² & $11.64(10.30,29.62)$ & $4.92(1.62,12.00)$ & 0.0336 \\
\hline MMP-9, \% & $15.87(5.59,29.61)$ & $2.90(0.72,9.93)$ & 0.0233 \\
\hline CXCL1, \% & $6.49(2.53,10.45)$ & $0.94(0.21,4.14)$ & 0.0106 \\
\hline Total collagen, \% & $11.10(8.29,16.39)$ & $19.39(11.45,41.55)$ & 0.0473 \\
\hline Aortic roots & & & \\
\hline Oil-red-0, $\times 10^{3} \mathrm{~mm}^{2}$ & $526.15(501.89,657.73)$ & $565.22(426.49,675.98)$ & 0.9759 \\
\hline Macrophage+ area, \% & $34.10(25.82,50.55)$ & $38.18(22.00,56.17)$ & 0.7399 \\
\hline Neutrophils/mm² & $35.90(12.82,68.57)$ & $9.40(2.66,19.32)$ & 0.0908 \\
\hline MMP-9, \% & $9.48(4.34,26.55)$ & $5.24(3.97,7.55)$ & 0.1179 \\
\hline CXCL1, \% & $6.82(3.48,17.35)$ & $3.32(0.08,10.02)$ & 0.0908 \\
\hline Total collagen, \% & $16.28(12.61,41.17)$ & $26.99(22.43,66.17)$ & 0.0688 \\
\hline Data are expressed as medians (interquartile range). ${ }^{2}$ MMP: matrix metalloproteinase. & \\
\hline & & & \\
\hline
\end{tabular}

Table 2: Parameters of mouse plaque vulnerability. 
Figure 1: FK866 treatment does not affect intraplaque lipids and macrophages. Representative microphotographs of mouse carotid (LSS and OSS regions) and aortic root plaques showing staining for lipids (A) or macrophages (B) in $\mathrm{Apo}^{-/-}$mice treated with Vehicle or FK866.

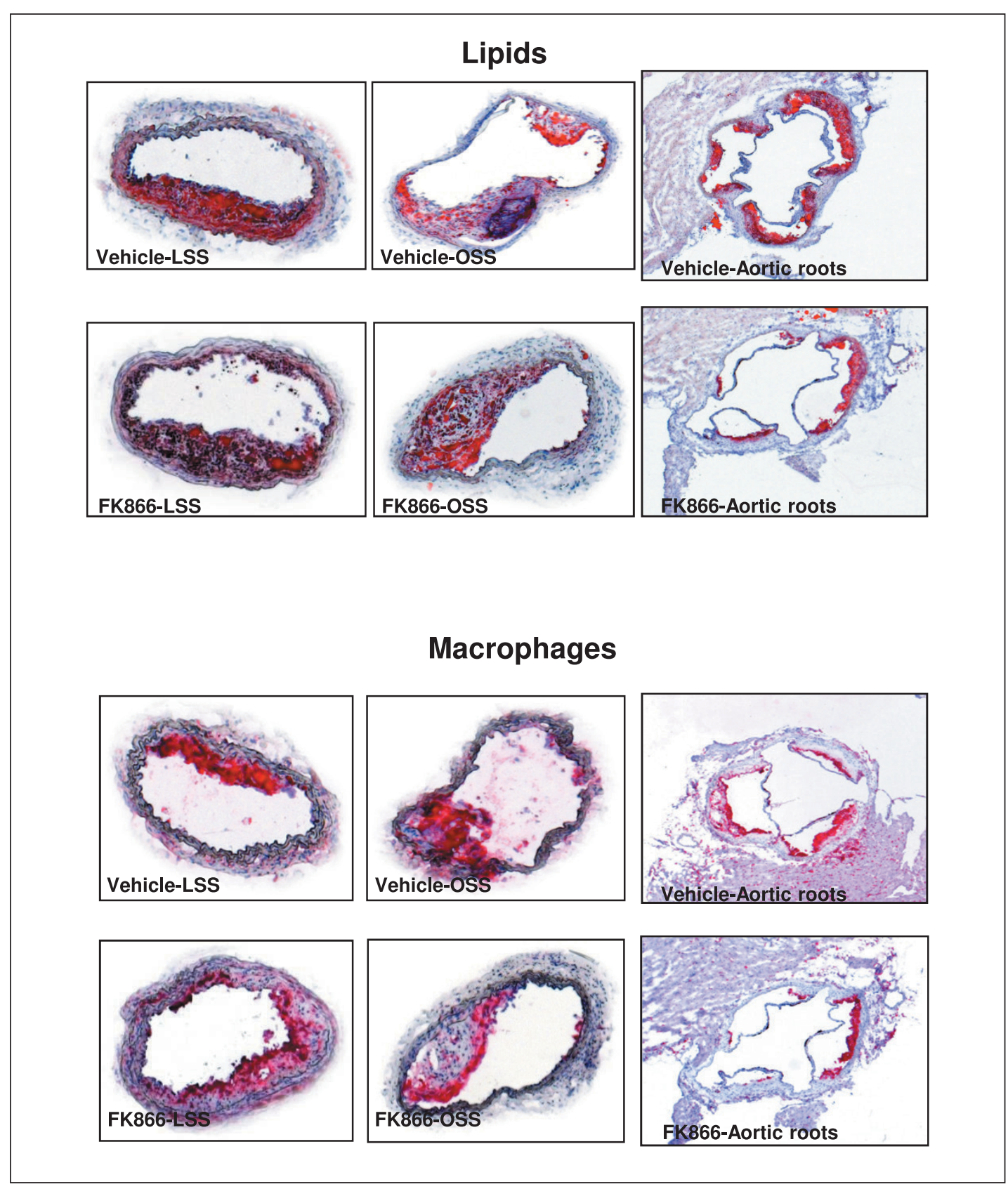

cast protocol ( Table 1). FK866 treatment did not have any effect on lipid content and macrophage infiltration in both carotid and aortic root plaques ( $>$ Table 2 , $>$ Figure $1 \mathrm{~A}$ and B). On the other hand, treatment with FK866 strongly reduced neutrophil, MMP-9 and CXCL1 content in carotid plaques (both LSS and OSS) as compared to control Vehicle ( $>$ Table 2, $>$ Figure 2A-C, $>$ Figure $3 \mathrm{~A}$ and B). Treatment with FK866 also determined a slight, nonsignificant reduction in these parameters in the aortic sinus ( $>$ Table 2, $>$ Figure 2A-C, $>$ Figure $3 \mathrm{~A}$ and B). In line with these findings, treatment with FK866 significantly increased the protective collagen content in OSS carotid plaques ( $>$ Table 2, $>$ Figure $4 \mathrm{~A}$ and $\mathrm{B})$. In order to exclude that the reduced levels of neutrophils in atherosclerotic plaques from FK866-treated mice could simply reflect an impaired bone marrow function with reduced neutrophil counts in the peripheral blood (possibility suggested by observations of a role for NAMPT in granulopoiesis) (22), we treated adult $\mathrm{ApoE}^{-/-}$mice that were on a high cholesterol diet with FK866 (or Vehicle) and monitored neutrophil and monocyte counts by both classical morphometric analysis and flow cytometry. Neither of these methods showed significant changes in neutrophil or monocyte representation in peripheral blood in FK866-treated mice compared to the Vehicle-treated controls ( Table 3, Suppl. Figure 1A and B, available online at www.throm bosis-online.com). This data is consistent with that of previous studies which also failed to notice major hematological side effects of FK866 at this dosage (2) and indicates that the observed reduc- 


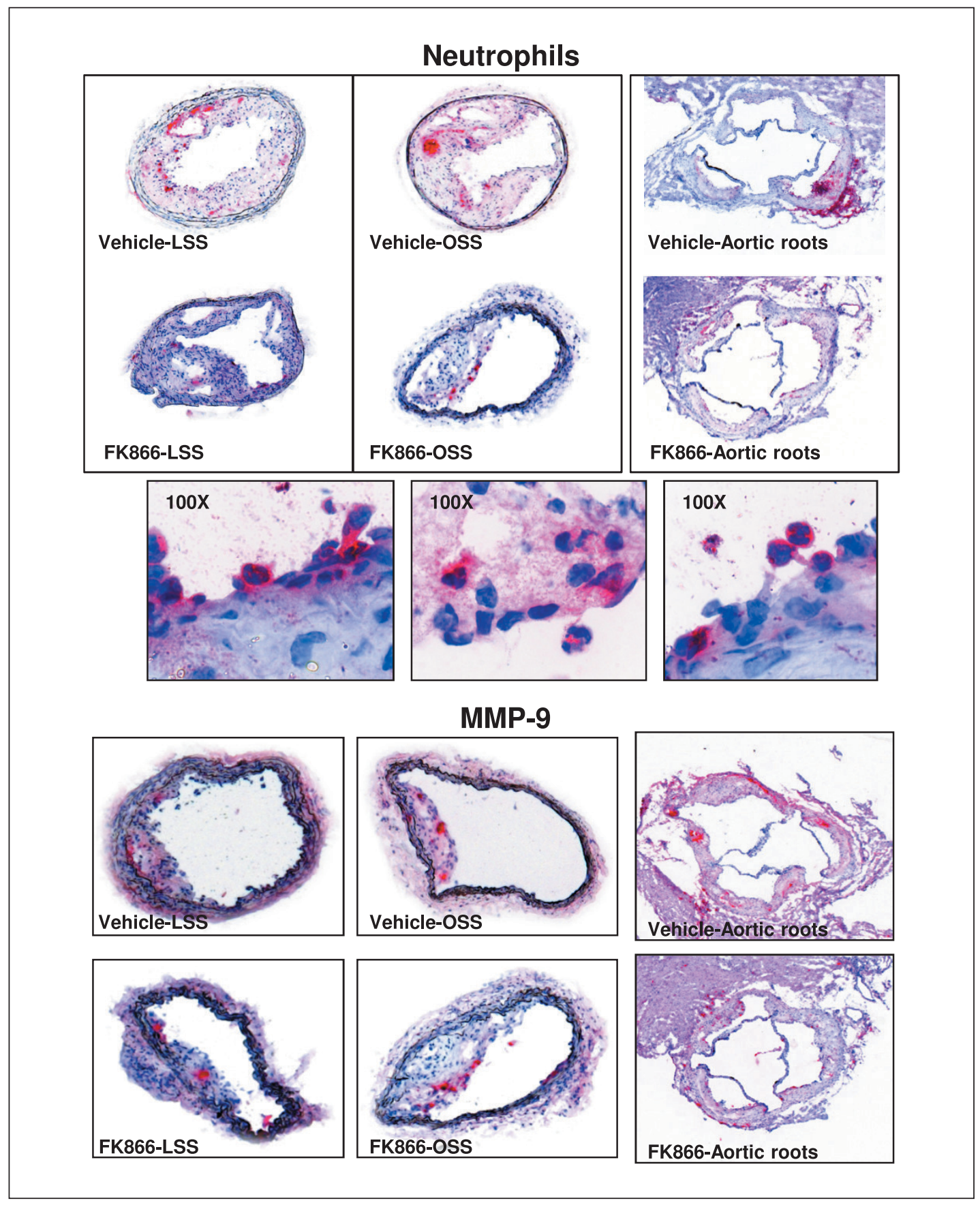

Figure 2: FK866 treatment reduces neutrophils and MMP-9 content within carotid plaques. Representative microphotographs of mouse carotid (LSS and OSS regions) and aortic root plaques showing staining for neutrophils (A, B) or MMP-9 (C) in $\mathrm{ApoE}^{-1-}$ mice treated with Vehicle or FK866. Specificity of the immunostaining for mouse neutrophil was confirmed at high magnification (100X) images showing the classical segmented nucleus.

tion in neutrophil infiltration and degranulation in carotid atherosclerotic lesions from FK866-treated mice was not due to major defects in neutrophil production.

\section{Treatment with FK866 does not affect neutrophil degranulation in vitro}

In view of the reduced MMP-9 levels that were detected in atherosclerotic plaques from FK866-treated mice, we aimed to assess whether these would be caused by an inhibition of neutrophil degranulation by FK866. Neutrophils have been recently shown as a major source of MMP-9 in mouse atherosclerotic plaques (10). In addition, these cells (but not macrophages) nicely co-localised with MMP-9 also in atherosclerotic plaques (consecutive cryosections) from both Vehicle- and FK866-treated animals under investigation in the present study ( $>$ Figure $5 \mathrm{~A}$ and $\mathrm{B}$ ). To this end, we used an in vitro model of human neutrophil degranulation (23). The latter were allowed to adhere in polystyrene wells in the presence or absence of TNF- $\alpha$, which is a well-known pro-atherosclerotic mediator (19). Neutrophil degranulation products were subsequently quantified in cell supernatants. Pre-treatment with FK866 did not significantly affect TNF-a-induced degranulation 
Figure 3: FK866 treatment reduces $\mathrm{CXCL} 1$ content within carotid plaques. Representative microphotographs of mouse carotid (LSS and OSS regions) and aortic root plaques showing staining for CXCL1 in ApoE $\mathrm{E}^{-1-}$ mice treated with Vehicle (A) or FK866 (B). High magnification (20X) images of aortic root images were shown for each mouse group.

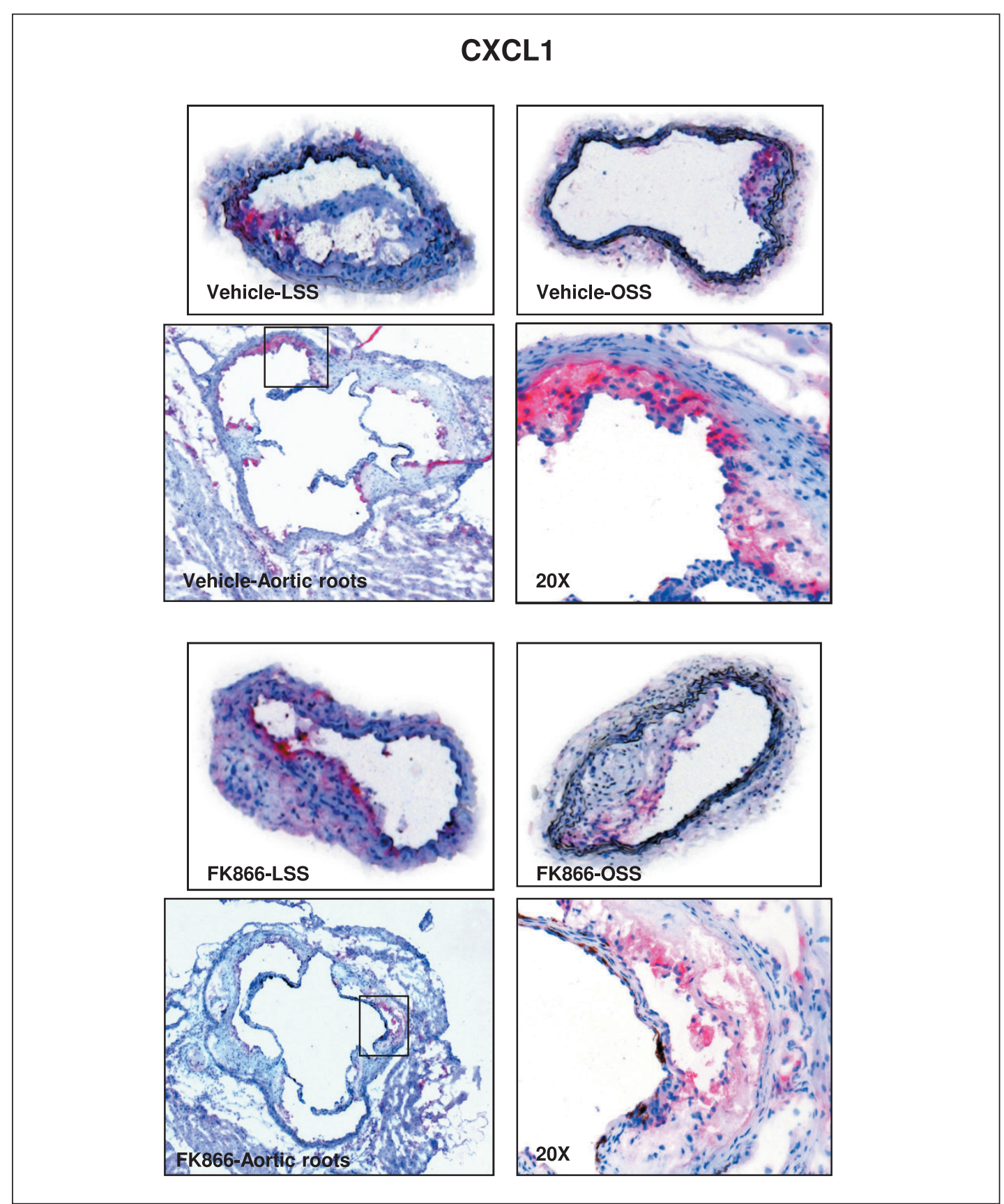

of primary (MPO), secondary (MMP-8), and tertiary granules (MMP-9) (Suppl. Figure 2A, B and C, respectively, available online at www.thrombosis-online.com). Accordingly, no significant difference in terms of pro-MMP-9 gelatinolytic activity could be detected among the same supernatants (Suppl. Figure 3A and B, available online at www.thrombosis-online.com). Similar results were obtained when PMA, instead of TNF- $\alpha$, was used to stimulate neutrophil degranulation (Suppl. Figure 4A-E, available online at www.thrombosis-online.com). Therefore, these results indicate that the reduced MMP-9 levels that were detected in plaques from FK866-treated mice are likely to reflect the reduced neutrophil in- filtration rather than impairment in neutrophil degranulation in response to NAMPT inhibition.

\section{Treatment with FK866 reduces endothelial cell production of the neutrophil chemoattractant CXCL1 by inhibiting NF-KB signalling}

Histological evaluations that were conducted to determine the cellular source of CXCL1 within atherosclerotic plaques demonstrated that this chemokine primarily co-localised with CD62E positive cells (activated endothelial cells) ( $>$ Figure 5A and B). In 


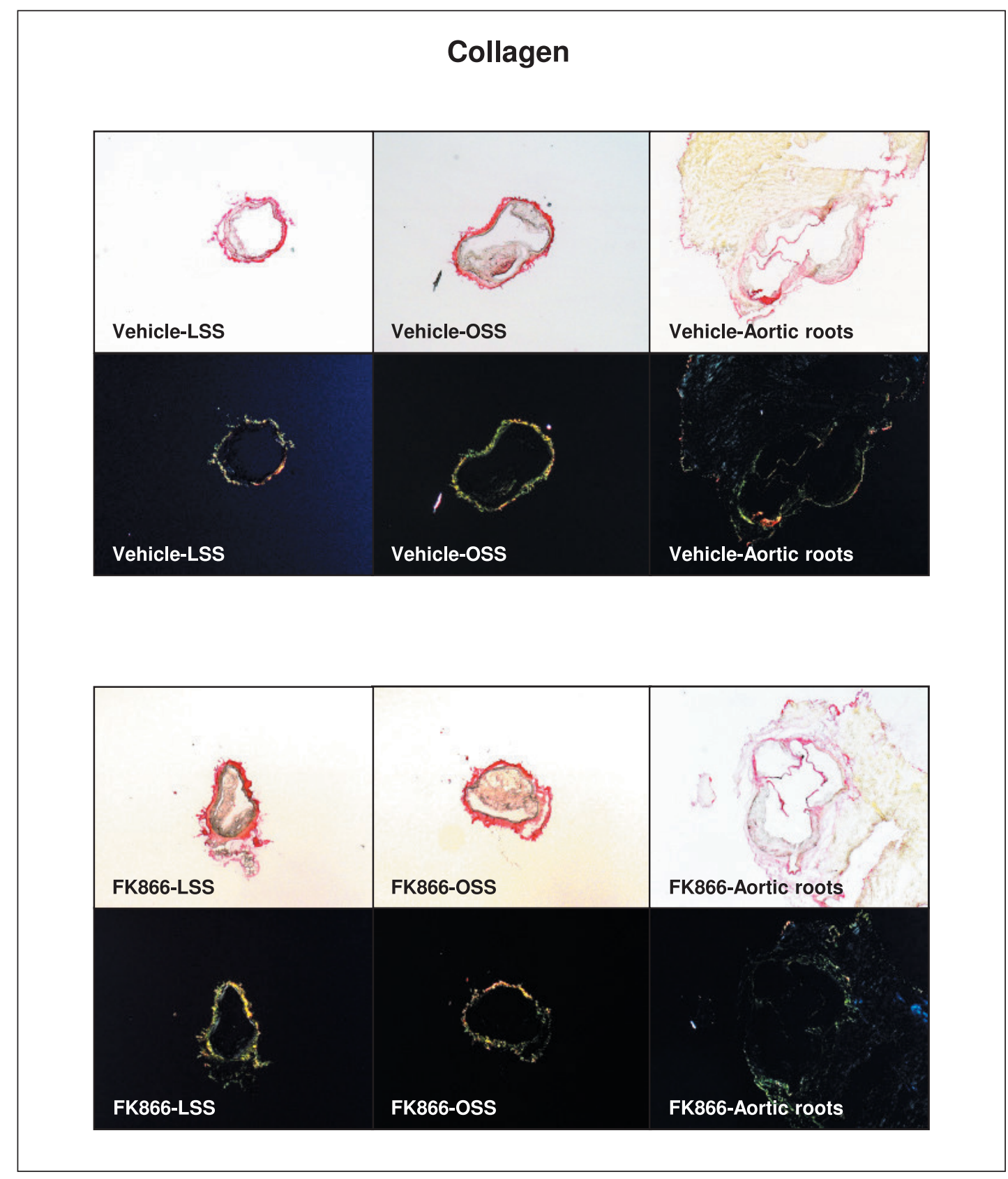

\begin{tabular}{|l|l|l|l}
\hline Haematological profile & Vehicle-treated mice $(\mathrm{n}=4)$ & FK866-treated mice $(\mathbf{n}=4)$ & P-value \\
\hline Haemoglobin $(\mathrm{g} / \mathrm{dl})$ & $10.8(9.9-11.7)$ & $10.4(9.5-10.7)$ & 0.2469 \\
\hline Red blood cells $\left(\mathrm{x} 10^{6} / \mathrm{ml}\right)$ & $7.68(6.75-7.95)$ & $7.49(7.04-8.04)$ & 0.8857 \\
\hline Platelets $\left(\mathrm{x} 10^{3} / \mathrm{ml}\right)$ & $870(837-942)$ & $1082(967-1404)$ & 0.0571 \\
\hline Total white blood cells $\left(\mathrm{x} 10^{3} / \mathrm{ml}\right)$ & $4.3(2.3-4.8)$ & $3.2(2.8-4.0)$ & 0.3851 \\
\hline Lymphocytes $\left(\times 10^{3} / \mathrm{ml}\right)$ & $3.22(1.74-3.31)$ & $2.29(1.82-3.12)$ & 0.6857 \\
\hline Neutrophils $\left(\times 10^{3} / \mathrm{ml}\right)$ & $0.36(0.17-0.58)$ & $0.28(0.25-0.30)$ & 0.3429 \\
\hline Monocytes $\left(\mathrm{x} 10^{3} / \mathrm{ml}\right)$ & $0.12(0.09-0.23)$ & $0.16(0.09-0.18)$ & 0.8857 \\
\hline Data are expressed as median (interquartile range). P-value calculated according to U Mann-Whitney test. & \\
\hline
\end{tabular}

Figure 4: FK866 treatment increases collagen content within OSS carotid plaques. Representative microphotographs of mouse carotid (LSS and OSS regions) and aortic root plaques showing staining for collagen in mice treated with Vehicle $(A)$ or FK8663 (B). Collagen specificity is shown under bright illumination without polarisation (upper part) and under polarised light illumination (lower part).

Table 3: Haematological parameters at sacrifice in adult hypercholesterolaemic ApoE ${ }^{-/-}$mice treated for five days with FK866 (10 mg/kg two times per day) or Vehicle (DMSO $0.1 \%$ in PBS). 
Figure 5: MMP-9 colocalises with neutrophils in mouse atherosclerotic plaques. Representative microphotographs of consecutive cryosections from root plaques of Vehicle (A) and FK866 (B)-treated mice for MMP-9, neutrophils (Ly-6G+ cells) and macrophages (CD68 ${ }^{+}$cells), respectively.

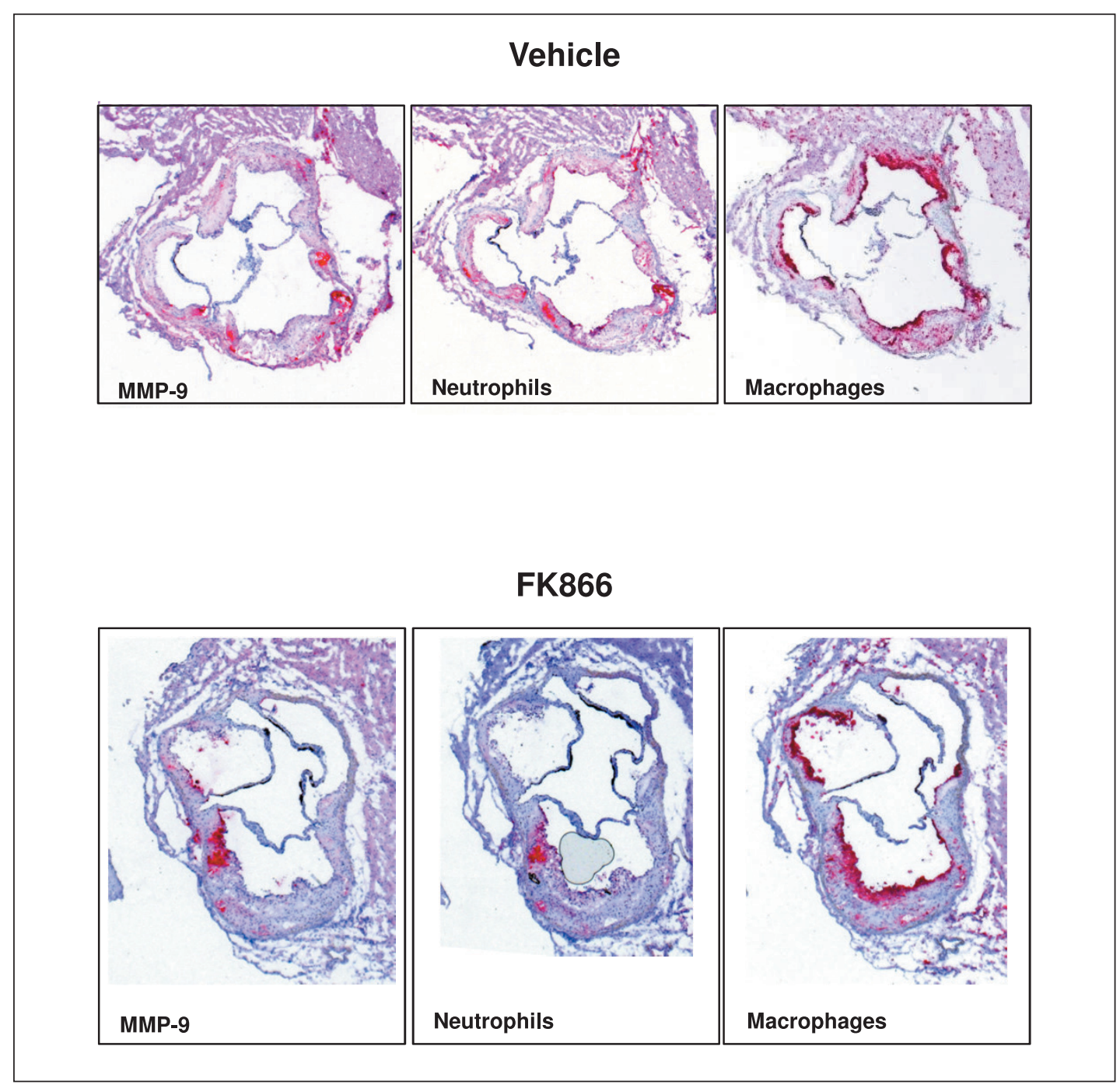

particular, CXCL1 and CD62E-positive areas in consecutive plaque sections from a Vehicle-treated $\mathrm{ApoE}^{-/}$mouse were found to exhibit a (pseudo) overlap of $78.4 \%$ on the endothelial surface. Thus, we directed subsequent investigations to confirm whether FK866 can interfere with chemokine (i.e. CXCL1) production by endothelial cells and to define the potential mechanism underlying this effect. To this end, endothelial HECV cells were utilised after verifying that these cells express NAMPT (whose expression was not affected by FK866) and that their NAMPT-dependent enzymatic pathway is active (shown by the marked reduction in intracellular $\mathrm{NAD}^{+}$levels in response to FK866) (Suppl. Figure 5A and $\mathrm{B}$, available online at www.thrombosis-online.com). HECV cells were pre-incubated with different doses of FK866 and subsequently stimulated with TNF-a. Consistent with our hypothesis, FK866 dose-dependently reduced CXCL1 ( $\$$ Figure 7A), but not CXCL8 (human homolog of mouse CXCL2) ( Figure 7B) nor CCL2 ( Figure 7C) secretion by endothelial cells. Importantly, reduced CXCL1 secretion by HVEC cells in response to FK866 was not to be ascribed to increased cell death, as shown by standard Annexin-V/PI viability assays (Suppl. Figure 6A and B, avail- able online at www.thrombosis-online.com). Consistent with this data, no difference in intraplaque apoptosis was detected between Vehicle- and FK866-treated mice in vivo (Suppl. Figure 7A and B, available online at www.thrombosis-online.com). Moreover, apoptotic (TUNEL positive) areas in atherosclerotic plaques did not colocalise within the endothelium (Suppl. Figure 7B, available online at www.thrombosis-online.com).

Previous studies indicated that the NF- $\kappa B$ p50/p65 heterodimer plays an important role in cytokine-induced Gro gene transcription $(24,25)$ and glucocorticoids were found to suppress Gro gene transcription through interference with the translocation of NF- $\mathrm{kB}$ p65 from the cytoplasm into the nucleus (26). Making use of the IkB kinase (IKK) inhibitor BAY 11-7082 (27), we effectively demonstrated that NF- $\mathrm{BB}$ plays a crucial role in CXCL1/Gro- $\alpha$ expression in endothelial cells, as shown by the markedly reduced levels of this chemokine in cells pretreated with the inhibitor ( Figure 8A). Finally, we sought to determine whether NAMPT inhibition with FK866 would interfere with NF- $\mathrm{kB}$ activation in HECV. By monitoring NF- $\mathrm{BB}$ p65 levels in nuclear extracts from these cells, we found that FK866 markedly reduced p65 nuclear 


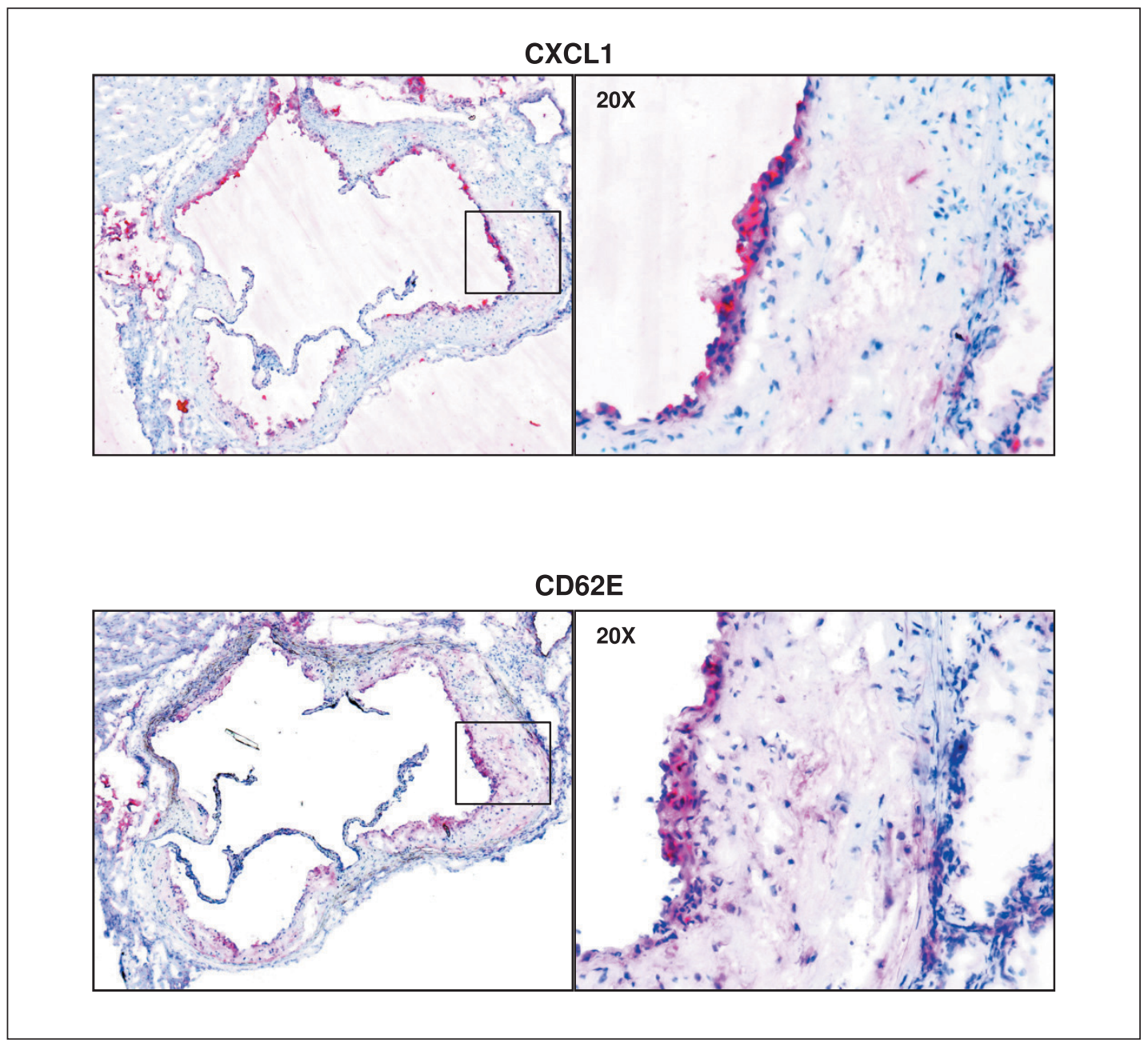

\author{
Figure 6: CXCL1 is \\ expressed in mouse \\ atherosclerotic \\ plaques and co-loca- \\ lises with activated \\ endothelial cells. A) \\ Representative micro- \\ photograph of CXCL1 \\ staining in aortic sinus \\ plaques of Vehicle-treated \\ ApoE ${ }^{-/-}$mice. Right panel \\ shows representative \\ higher magnifications \\ (20X) of stained regions. \\ B) Representative micro- \\ photograph of a consecu- \\ tive cryosection from the \\ same atherosclerotic \\ plaque for CD62E (marker \\ of activated endothelial \\ cells). Right panel shows \\ representative higher \\ magnifications (20X) of \\ stained regions.
}

translocation in response to TNF- $\alpha$ stimulation ( $>$ Figure $8 \mathrm{~B}$ and C). Taken together, these findings are consistent with FK866 prevention of CXCL1 production being mediated through NF- $\kappa \mathrm{B}$ inhibition.

\section{Discussion}

In our study, we demonstrated that pharmacological inhibition of the enzymatic activity of NAMPT specifically reduces CXCL1 levels in the serum and in atherosclerotic plaques, thus avoiding neutrophil migration into atheromas. These findings were associated with strong improvements in plaque vulnerability parameters (such as MMP-9 and collagen content) in carotid plaques. In addition, our data identify in NF- $\kappa B$ signalling obstruction a mechanism through which NAMPT inhibition is likely to selectively affect CXCL1 production and, consequently, neutrophil migration into atherosclerotic plaques.

This study is in line with and further extends our previous observations that were obtained in a myocardial ischaemia/reperfusion model and clearly indicated the potential of NAMPT in- hibition to selectively affect neutrophil attraction to the infarcted myocardium by reducing the levels of another chemoattractant, CXCL2 (2). Notably, while in that study, reduced SIRT6 activity was proposed as a mechanism for the reduced levels of CXCL2 that were detected in FK866-treated animals, here, we found no apparent correlation between SIRT6 levels and CXCL1 production in endothelial cells, since SIRT6 silencing failed to recreate the effects of FK866 in terms of CXCL1 synthesis inhibition (data not shown). Instead, we found that NAMPT inhibition is likely to reduce CXCL1 expression in endothelial cells by dampening NF- $\kappa \mathrm{B}$ signalling. Evidence in support of this conclusion was, on the one hand, the ability of FK866 to inhibit NF- $\mathrm{BB}$ p65 nuclear translocation and, on the other hand, the finding that NF- $\kappa B$ signalling inhibition (with BAY 11-7082) reduces CXCL1 production by endothelial cells. These findings are consistent with previous studies reporting a defective NF- $\mathrm{kB}$ activation in cells that were exposed to NAMPT inhibitors and indicate that intracellular $\mathrm{NAD}^{+}$levels are also important in regulating the activation of this crucial proinflammatory signal transduction pathway in endothelial cells (28-30). Notably, although FK866 and NF- $\mathrm{kB}$ inhibitors were reported to affect cell viability, we could not detect any increase in 
apoptotic endothelial cells in response to the NAMPT inhibitor, both in vitro and in vivo. Thus, the observed reduction in CXCL1 production in response to FK866 (via inhibition of NF- $\mathrm{B}$ p $65 \mathrm{nu}-$ clear translocation) appears to solely reflect a functional impairment rather than reduced cell viability.

FK866 beneficial activity in terms of a reduction in plaque vulnerability parameters was not accounted for by reduced levels of circulating neutrophils or monocytes in FK866-trated mice, nor by impairment in neutrophil function since the NAMPT inhibitor failed to affect neutrophil degranulation in vitro. Consistent with this data, others had previously failed to document changes in blood cell counts in animals treated with FK866 at the dosage used in this study (2), while we had previously reported that FK866 does not to accelerate neutrophil apoptosis nor does it reduce reactive oxygen species production by these cells (4). Therefore, the improvement in atherosclerotic plaque vulnerability parameters appears to solely reflect the ability of FK866 to reduce CXCL1 production and, consequently, potential neutrophil attraction within the plaque. Notably, NAMPT-mediated $\mathrm{NAD}^{+}$biosynthesis seems to be selectively required for the production of defined chemoattractants, but not for others. Namely, while CXCL1 levels were strongly reduced by FK866, the levels of CCL2 (a monocyte chemotactic protein) were not. On the other hand, macrophage recruitment within atheromas was not affected by FK866 treatment in the different plaque phenotypes. Considering that CXCL1/CXCR2 axis was also shown as be critical in macrophage accumulation within established fatty streak lesions $(31,32)$, our data might be quite surprising. However, as recently shown in mouse models of acute cardiovascular diseases using selective CXC chemokine antagonists $(12,33)$, no significant decrease in tissue macrophage content was observed when CXCL1 activity was abrogated. Interestingly, we also showed a non-significant reduction in macrophage accumulation in LSS carotid plaques (more vulnerable), suggesting that this chemokine might play a different role for macrophages in different plaque phenotypes. Potential rebound of other chemoattractants as a consequence of CXCL1 abrogation (34) or interference of circulating lipids on neutrophil migration (35) might explain our results on macrophage pathophysiology. However, a specific dependence of neutrophil chemotactic stimuli on NAMPT activity emerges from these investigations. Finally, despite the well-established role of NADP $(\mathrm{H})$ in lipid biosynthesis (36), FK866 did not show lipidlowering effects and the lipid content of atherosclerotic plaques was also not affected by treatment with FK866. The NAMPT inhibitor failed to modify total, LDL, or HDL cholesterol and free fatty acid serum levels while, in the case of serum triglycerides, we even detected an increase in response to this agent. These findings could partly be explained by our previous observation that the $\operatorname{NADP}(\mathrm{H})$ pool is less affected by protracted NAMPT inhibition as compared to the $\mathrm{NAD}(\mathrm{H})$ pool (2), possibly allowing for lipid biosynthetic reactions to continue. Alternatively, it could be imagined that lipid catabolic reactions, which are highly dependent on $\mathrm{NAD}^{+}$, may be dampened by FK866, possibly justifying the persistence of elevated lipid serum levels despite a concomitant reduction in lipid biosynthesis.

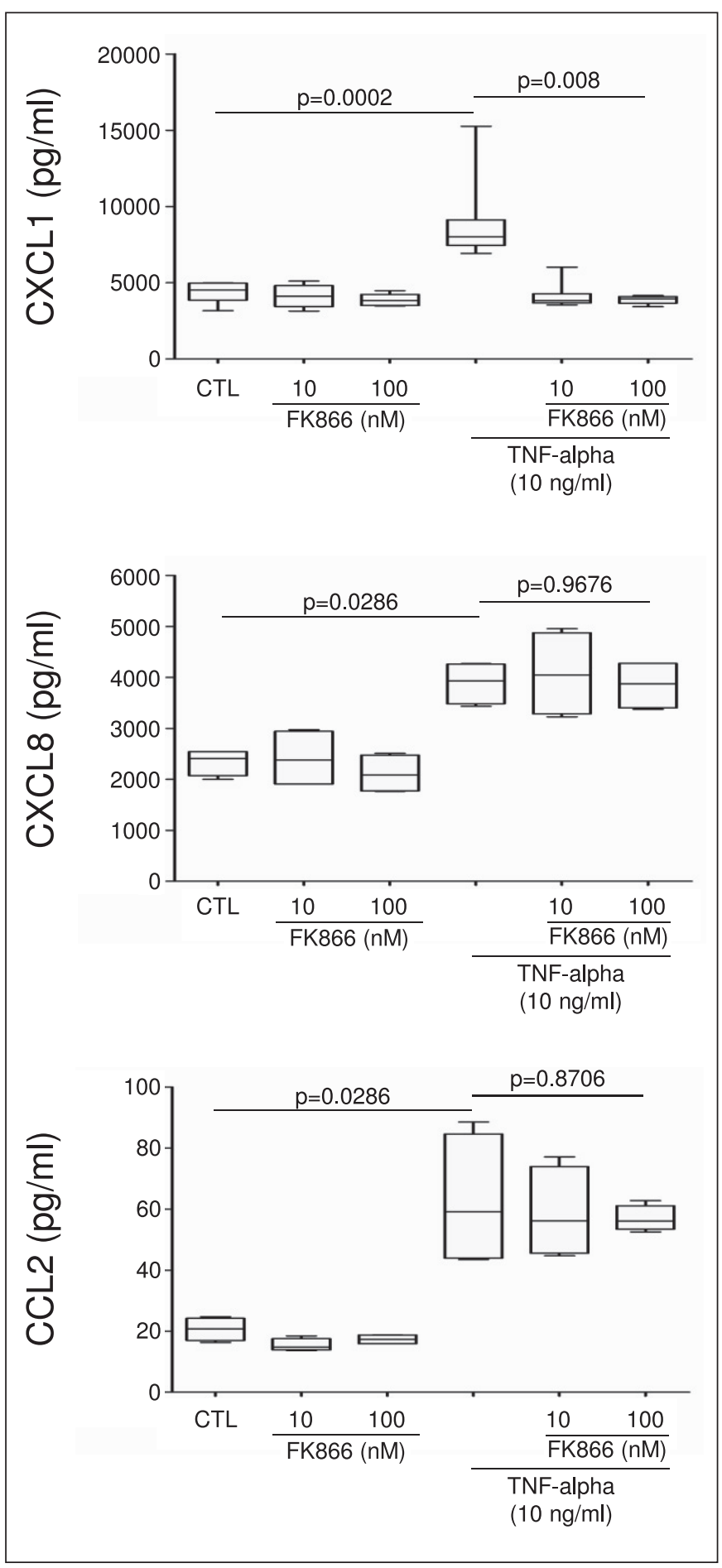

Figure 7: Pre-treatment with FK866 inhibits CXCL1 production in TNF- $\alpha$ stimulated endothelial cells. HECV endothelial cells were pre-incubated for $24 \mathrm{~h}$ with the indicated concentrations of FK866 and then stimulated with or without (control, CTL), $10 \mathrm{ng} / \mathrm{ml}$ TNF- $\alpha$. At $24 \mathrm{~h}$ later, supernatants were collected and CXCL1 (A), CXCL8 (B) and CCL2 (C) levels were quantified by ELISA. Data are expressed as median (interquartile range) of chemokine release in cell supernatants ( $n=8$ for CXCL1 and $n=4$ for CXCL8 and $(\mathrm{CL} 2)$. 


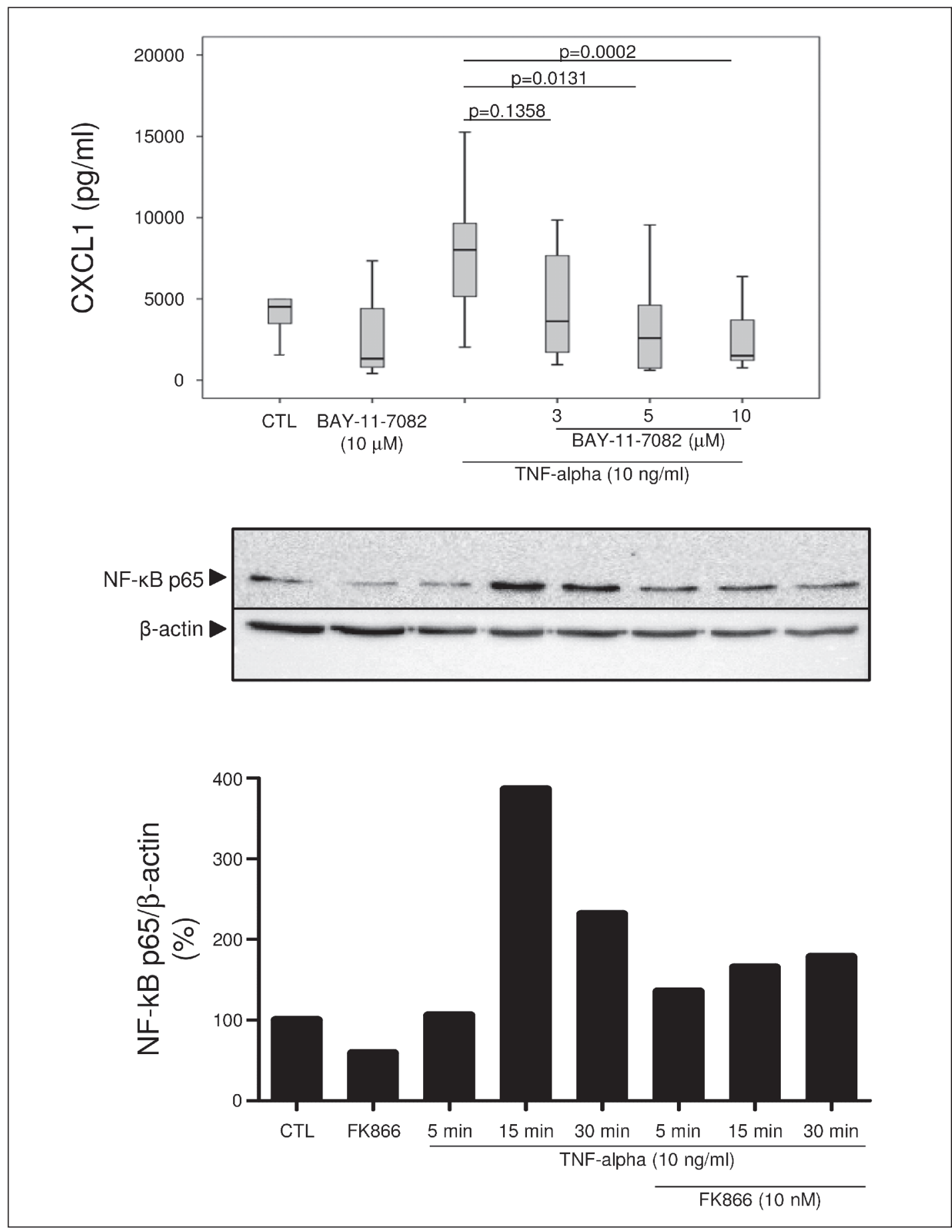

Figure 8: FK866 reduces CXCL1 production in endothelial cells through NF-KB signalling obstruction. A) HECV cells were preincubated for $30 \mathrm{~min}$ with the indicated concentrations of BAY-11-7082 and then stimulated with or without (control, CTL) 10 ng/ml TNF-a. Supernatants were collected $24 \mathrm{~h}$ later and CXCL1 levels were quantified by ELISA. Data are expressed as median (interquartile range) of CXCL1 release in cell supernatants $(n=8) . B, C)$ HECV cells were pre-incubated for 48 $\mathrm{h}$ with $10 \mathrm{nM}$ FK866 and then stimulated with or without (control, CTL) 10 $\mathrm{ng} / \mathrm{ml}$ TNF- $\alpha$ for the indicated amounts of time. Thereafter, cells were used for nuclear extract preparation and NF-KB p65 and $\beta$-actin levels were quantified by immunoblotting. B) One representative experiment out of three is presented. C) Densitometry of the immunoblotting.

The limitations of this study include the relatively low number of mice per treatment group (conform to $3 \mathrm{R}$ principles) and the possibility that the vehicle DMSO per se may have exerted some pro-inflammatory effects inside the plaque, as suggested by a comparison of the intraplaque vulnerability parameters from this study (from both groups of animals) with historical experiments in which PBS, instead of DMSO, was used as a vehicle (12). Nevertheless, since similar (and relatively small) amounts of vehicle
DMSO were administered to both study groups, we believe that the conclusions of this study are valid and of strong significance.

We conclude that pharmacological NAMPT inhibition can be considered as a promising approach to interfere with important pro-inflammatory signalling pathways and to selectively reduce both systemic and intraplaque CXCL1 levels. The resulting interference of CXCL1-mediated activities on leukocytes (i.e. neutrophils that are a major source of MMP-9) (10) into atheromas could 


\section{What is known about this topic?}

- Atherogenesis is regulated by inflammatory processes that are still unknown.

- CXC and CC chemokines attract and activate leukocytes within atherosclerotic plaques.

\section{What does this paper add?}

- Pharmacological inhibition of nicotinamide phosphoribosyltransferase (NAMPT) is associated with reduction of CXCL1 levels in the systemic circulation and within atherosclerotic plaques in atherosclerotic mice.

- The reduction of systemic and intraplaque CXCL1 levels results in a less vulnerable phenotype of atherosclerotic plaques.

be clinically relevant and should be further investigated. Importantly, when thinking of this type of clinical applications for NAMPT inhibitors, it should be kept in mind that these agents may have significant side effects, including immunosuppressive effects (1-3). Thus, for instance, the placement of a stent coated with FK866 after a myocardial infarction (with a local intraplaque activity) might be safer and even more effective than the systemic administration of this agent.

\section{Acknowledgements}

This research was funded by the Brazilian Swiss Joint Research Program (BSJRP) (to Drs. F. Mach, N. Stergiopulos, and A.S. Robson), by the EU FP7 (Grant number 201668, AtheroRemo to Dr. F. Mach), by the Swiss National Science Foundation (grant \#310030-118245 to Dr. F. Mach and grant \#32003B-134963/1 to Dr. F. Montecucco), by Novartis Foundation (grant to Dr. F. Montecucco), by Foundation "Gustave and Simone Prévot" to Dr. F. Montecucco, by the Italian Ministry of Health (grant GR-2008-1135635 to Dr. A. Nencioni) and by the University of Genoa (to Drs. F. Montecucco and A. Nencioni).

\section{Conflicts of interest}

None declared.

\section{References}

1. Van Gool F, Gallí M, Gueydan C, et al. Intracellular NAD levels regulate tumor necrosis factor protein synthesis in a sirtuin-dependent manner. Nat Med 2009; 15: 206-210.

2. Busso N, Karababa M, Nobile M, et al. Pharmacological inhibition of nicotinamide phosphoribosyltransferase/visfatin enzymatic activity identifies a new inflammatory pathway linked to NAD. PLoS One 2008; 3: e2267.

3. Bruzzone S, Fruscione F, Morando S, et al. Catastrophic NAD+ depletion in activated T lymphocytes through NAMPT inhibition reduces demyelination and disability in EAE. PLoS One 2009; 4: e7897.

4. Montecucco F, Bauer I, Braunersreuther V, et al. Inhibition of nicotinamide phosphoribosyltransferase reduces neutrophil-mediated injury in myocardial infarction. Antioxid Redox Signal 2013; 18: 630-641.
5. Hasmann M, Schemainda I. FK866, a highly specific noncompetitive inhibitor of nicotinamide phosphoribosyltransferase, represents a novel mechanism for induction of tumor cell apoptosis. Cancer Res 2003; 63: 7436-7442.

6. Moschen AR, Gerner R, Schroll A, Fritz T, Kaser A, Tilg H. A key role for Pre-B cell colony-enhancing factor in experimental hepatitis. Hepatology 2011; 54: 675-686.

7. Weber C, Noels H. Atherosclerosis: current pathogenesis and therapeutic options. Nat Med 2011; 17: 1410-1422.

8. Koenen RR, Weber C. Chemokines: established and novel targets in atherosclerosis. EMBO Mol Med 2011; 3: 713-725.

9. Soehnlein O. Multiple roles for neutrophils in atherosclerosis. Circ Res 2012; 110: 875-888.

10. Montecucco F, Di Marzo V, da Silva RF, et al. The activation of the cannabinoid receptor type 2 reduces neutrophilic protease-mediated vulnerability in atherosclerotic plaques. Eur Heart J 2012; 33: 846-856.

11. Montecucco F, Lenglet S, Gayet-Ageron A, et al. Systemic and intraplaque mediators of inflammation are increased in patients symptomatic for ischaemic stroke. Stroke 2010; 41: 1394-1404.

12. Copin JC, da Silva RF, Fraga-Silva RA, et al. Treatment with Evasin-3 reduces atherosclerotic vulnerability for ischaemic stroke, but not brain injury in mice. Cereb Blood Flow Metab 2013; 33: 490-498.

13. Koenen RR, Weber C. Manipulating the chemokine system: therapeutic perspectives for atherosclerosis. Curr Opin Investig Drugs 2010; 11: 265-272.

14. Koenen RR, Weber C. Therapeutic targeting of chemokine interactions in atherosclerosis. Nat Rev Drug Discov 2010; 9: 141-153.

15. Dahl TB, Yndestad A, Skjelland M, et al. Increased expression of visfatin in macrophages of human unstable carotid and coronary atherosclerosis: possible role in inflammation and plaque destabilisation. Circulation 2007; 115: 972-980.

16. Cheng C, Tempel D, van Haperen R, et al. Atherosclerotic lesion size and vulnerability are determined by patterns of fluid shear stress. Circulation 2006; 113: 2744-2753.

17. Lenglet S, Thomas A, Soehnlein O, et al. Fatty acid amide hydrolase deficiency enhances intraplaque neutrophil recruitment in atherosclerotic mice. Arterioscler Thromb Vasc Biol 2013; 33: 215-223.

18. van Leeuwen M, Gijbels MJ, Duijvestijn A, et al. Accumulation of myeloperoxidase-positive neutrophils in atherosclerotic lesions in LDLR-/- mice. Arterioscler Thromb Vasc Biol 2008; 28: 84-89.

19. Polykratis A, van Loo G, Xanthoulea S, Hellmich M, Pasparakis M. Conditional targeting of tumor necrosis factor receptor-associated factor 6 reveals opposing functions of Toll-like receptor signalling in endothelial and myeloid cells in a mouse model of atherosclerosis. Circulation 2012; 126: 1739-1751.

20. Skehan P, Storeng R, Scudiero D, et al. New colorimetric cytotoxicity assay for anticancer-drug screening. J Natl Cancer Inst 1990; 82: 1107-1112.

21. Graeff R, Lee HC. A novel cycling assay for cellular cADP-ribose with nanomolar sensitivity. Biochem J 2002; 361: 379-384.

22. Skokowa J, Lan D, Thakur BK, et al. NAMPT is essential for the G-CSF-induced myeloid differentiation via a $\mathrm{NAD}(+)$-sirtuin-1-dependent pathway. Nat Med 2009; 15: 151-158.

23. Quercioli A, Mach F, Bertolotto M, et al. Receptor activator of NF- $\kappa B$ ligand (RANKL) increases the release of neutrophil products associated with coronary vulnerability. Thromb Haemost 2012; 107: 124-139.

24. Shattuck RL, Wood LD, Jaffe GJ, Richmond A. MGSA/GRO transcription is differentially regulated in normal retinal pigment epithelial and melanoma cells. Mol Cell Biol 1994; 14: 791-802.

25. Wood LD, Farmer AA, Richmond A. HMGI(Y) and Spl in addition to NFkappa B regulate transcription of the MGSA/GRO alpha gene. Nucleic Acids Res 1995; 23: 4210-4219.

26. Ohtsuka T, Kubota A, Hirano T, et al. Glucocorticoid-mediated gene suppression of rat cytokine-induced neutrophil chemoattractant CINC/gro, a member of the interleukin-8 family, through impairment of NF-kappa B activation. J Biol Chem 1996; 271: 1651-1659.

27. Pierce JW, Schoenleber R, Jesmok G, et al. Novel inhibitors of cytokine-induced IkappaBalpha phosphorylation and endothelial cell adhesion molecule expression show anti-inflammatory effects in vivo. J Biol Chem 1997; 272: 21096-21103.

28. Olsen LS, Hjarnaa PJ, Latini S, et al. Anticancer agent CHS 828 suppresses nuclear factor-kappa B activity in cancer cells through downregulation of IKK activity. Int J Cancer 2004; 111: 198-205. 
29. Hassan SB, Lövborg H, Lindhagen E, et al. CHS 828 kill tumour cells by inhibiting the nuclear factor-kappaB translocation but unlikely through downregulation of proteasome. Anticancer Res 2006; 26: 4431-4436.

30. Esposito E, Impellizzeri D, Mazzon E, et al. The NAMPT inhibitor FK866 reverts the damage in spinal cord injury. J Neuroinflammation 2012; 9: 66.

31. Soehnlein O, Drechsler M, Döring Y, et al. Distinct functions of chemokine receptor axes in the atherogenic mobilisation and recruitment of classical monocytes. EMBO Mol Med 2013; 5: 471-481.

32. Boisvert WA, Rose DM, Johnson KA, et al. Up-regulated expression of the CXCR2 ligand KC/GRO-alpha in atherosclerotic lesions plays a central role in macrophage accumulation and lesion progression. Am J Pathol 2006; 168: 1385-1395.
33. Montecucco F, Lenglet S, Braunersreuther V, et al. Single administration of the CXC chemokine-binding protein Evasin-3 during ischaemia prevents myocardial reperfusion injury in mice. Arterioscler Thromb Vasc Biol 2010; 30: 1371-1377.

34. Wan W, Murphy PM. Regulation of atherogenesis by chemokines and chemokine receptors. Arch Immunol Ther Exp 2013; 61: 1-14.

35. Drechsler M, Megens RT, van Zandvoort M, et al. Hyperlipidemia-triggered neutrophilia promotes early atherosclerosis. Circulation 2010; 122: 1837-1845.

36. Shimomura I, Shimano H, Korn BS, et al. Nuclear sterol regulatory elementbinding proteins activate genes responsible for the entire program of unsaturated fatty acid biosynthesis in transgenic mouse liver. J Biol Chem 1998; 273: 35299-35306.

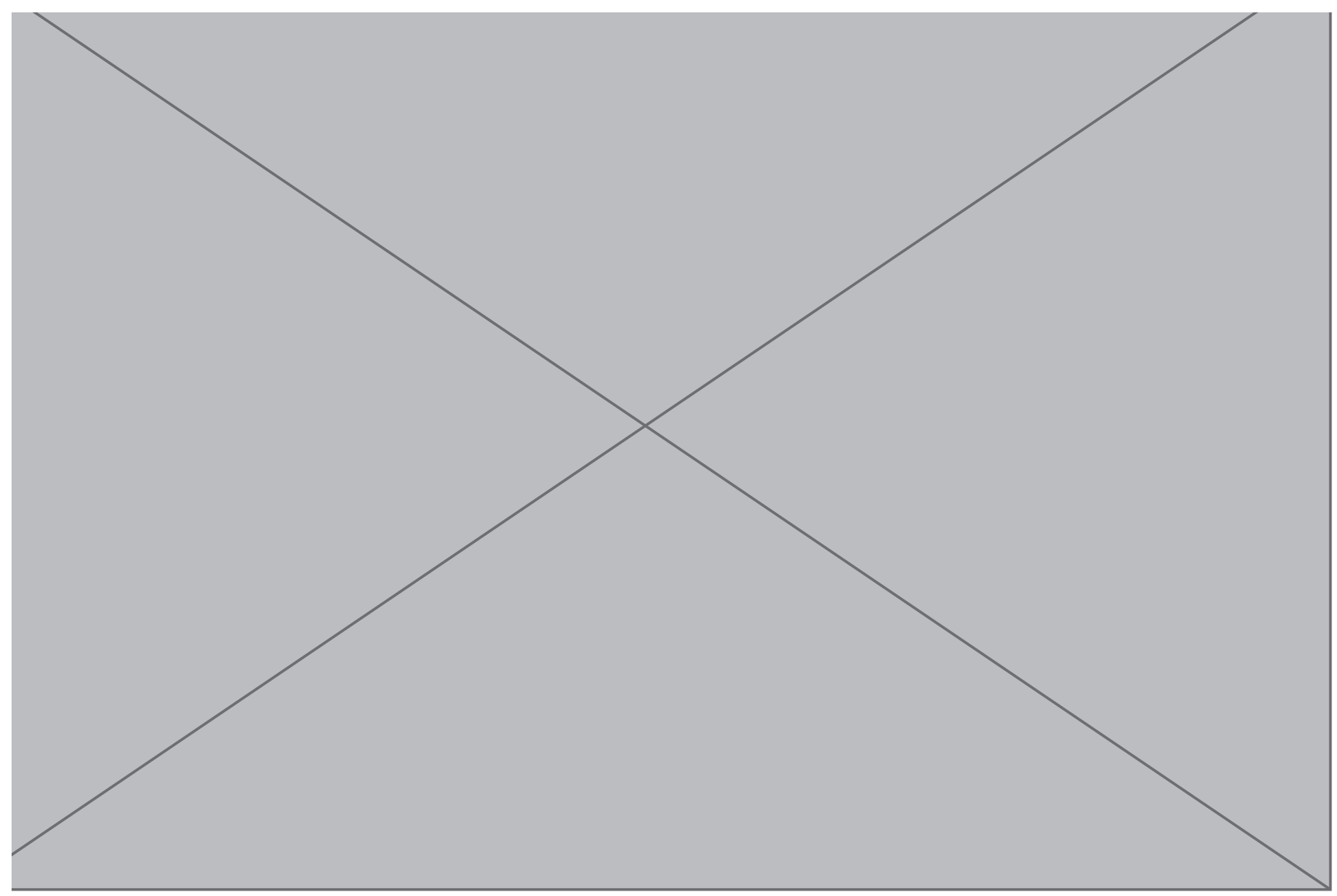

